\title{
Review
}

\section{Potential therapeutics specific to c-MET/RON receptor tyrosine kinases for molecular targeting in cancer therapy}

\author{
Ming-Hai WANG ${ }^{1, *}$, Snehal S PADHYE ${ }^{1}$, Sunny GUIN ${ }^{1}$, Qi MA ${ }^{1}$, Yong-qing ZHOU ${ }^{2, *}$
}

\begin{abstract}
${ }^{1}$ Center for Cancer Biology \& Therapeutics and Department of Biomedical Sciences, School of Pharmacy, Texas Tech University Health Sciences Center, Amarillo, TX 79106, USA; ${ }^{2}$ Division of Neurosurgery, First Affiliated Hospital of Zhejiang University School of Medicine, Hangzhou 310003, China
\end{abstract}

Products of proto-oncogenes c-MET and RON belong to a subfamily of receptor tyrosine kinases that contribute significantly to tumorigenic progression. In primary tumors, altered c-MET/RON expression transduces signals regulating invasive growth that is characterized by cell migration and matrix invasion. These pathogenic features provide the basis for targeting c-MET/RON in cancer therapy. In the last decade, various approaches have been investigated to suppress c-MET/RON-transduced oncogenesis. Among the therapeutics developed, monoclonal antibodies (mAbs) and small-molecule inhibitors (SMIs) have emerged as promising candidates. The mechanism of these therapeutic candidates is the disruption of tumor dependency on c-MET/RON signals for survival. The mAbs specific to hepatocyte growth factor (AMG102) and c-MET (MetMAb) are both humanized and able to block c-MET signaling, leading to inhibition of tumor cell proliferation in vitro and inhibition of tumor growth in xenograft models. The mAb AMG102 neutralizes hepatocyte growth factor and enhances the cytotoxicity of various chemotherapeutics to tumors in vivo. AMG102 is currently in phase II clinical trials for patients with advanced solid tumors. IMC-41A40 and Zt/f2 are RON-specific mAbs that downregulate RON expression and inhibit ligand-induced phosphorylation. Both mAbs inhibit tumor growth in mice mediated by colon and pancreatic cancer cells. SMIs specific to C-MET (ARQ107 and PF-02341066) are in various phases of clinical trials. Therapeutic efficacy has also been observed with dual inhibitors such as Compound I, which is specific to c-MET/RON. However, a potential issue is the emergence of acquired resistance to these inhibitors. Clearly, development of c-MET/RON therapeutics provides opportunities and challenges for combating cancer in the future.

Keywords: receptor tyrosine kinase; therapeutic antibody; tyrosine kinase inhibitor; targeted cancer therapy; cellular mechanism; acquired resistance

Acta Pharmacologica Sinica (2010) 31: 1181-1188; doi: 10.1038/aps.2010.106; published online 9 Aug 2010

\section{Introduction}

Molecular-targeted cancer therapy is an advanced antineoplastic strategy used in clinical practice. By acting on particular tumorigenic molecules, targeted therapeutics directly inhibit cellular growth and survival machinery to eradicate tumor cells and thereby achieve clinical significance. Applications of monoclonal antibodies (mAbs) and small-molecule inhibitors (SMIs) such as trastuzumab and lapatinib in the treatment of various solid tumors are ideal examples ${ }^{[1]}$. These drugs target tumors via cell surface proteins known as recep-

\footnotetext{
* To whom correspondence should be addressed.

E-mail zhouyq56@hotmail.com (Yong-qing ZHOU); minghai.wang@ttuhsc.edu (Ming-Hai WANG)

Received 2010-05-25 Accepted 2010-07-01
}

tor tyrosine kinases (RTKs) and their connate ligands ${ }^{[2]}$. Epidermal growth factor receptor (EGFR), vascular endothelial growth factor (VEGF), VEGF receptors, and other ligands and receptors are currently being targeted with $\mathrm{mAbs}$ and SMI for clinical cancer treatment ${ }^{[1,2]}$. Other RTKs and their specific ligands such as c-MET and hepatocyte growth factor (HGF) are also targets that are under intensive clinical evaluation ${ }^{[3,4]}$.

RTKs have unique structural and biochemical features that transduce extracellular signals into intracellular compartments ${ }^{[5]}$. The evidence of RTK involvement in cancer progression is well documented ${ }^{[6,7]}$. Aberrant RTK expression and activity are directly linked to various stages of cancer development, from cell transformation in situ to distant metastasis in remote organs ${ }^{[8,9]}$. These findings led to the establishment of the oncogene addiction theory ${ }^{[10]}$, which provides the theoreti- 
cal basis for the development of molecular-based therapeutics for targeted cancer therapy.

This review focuses on the progress of potential therapeutics that target a unique subfamily of RTKs known as the c-MET proto-oncogene family, including two of its members, c-MET and $\mathrm{RON}^{[11,12]}$. Genetic and biological studies have revealed that altered $\mathrm{c}-\mathrm{MET} / \mathrm{RON}$ expression contributes to the pathogenesis of various epithelial cancers ${ }^{[11,12]}$. Oncogenic addiction of tumor cells to c-MET/RON signaling for survival and growth has also been demonstrated ${ }^{[13]}$. Moreover, pharmacological inhibition of c-MET/RON pathways has achieved therapeutic benefits in various animal xenograft models and in human cancer patients ${ }^{[3,14,15]}$. Thus, the use of therapeutics targeting c-MET/RON signaling is a promising approach for the treatment of malignant cancers.

\section{C-MET/RON in tumor pathogenesis and signaling addic- tion}

c-MET and RON share similar structural and biochemical properties (Figure 1) ${ }^{[16,17]}$. Both proteins are heterodimers composed of a $\sim 40-\mathrm{kDa}$ extracellular a-chain and a $\sim 150-\mathrm{kDa}$ transmembrane $\beta$-chain with intrinsic tyrosine kinase activ-

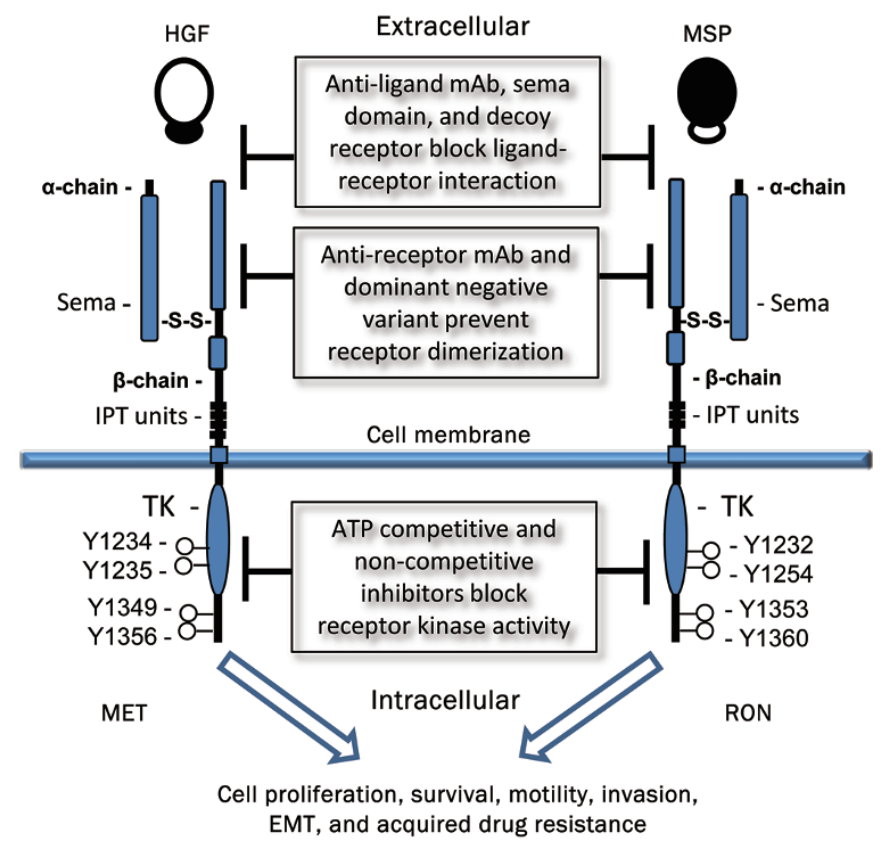

Figure 1. Schematic representation of the structures of human c-MET, RON, and potential signaling inhibition strategies. Mature c-Met/RON composed of an extracellular $\alpha$-chain and a transmembrane $\beta$-chain with intrinsic tyrosine kinase (TK) activity. The extracellular sequences of C-MET/RON contain several functional domains, including sema, PSI and immunoglobulin-like plexin transcription (IPT) units. Binding of HGF or MSP results in the c-MET/RON auto-phosphorylation of several tyrosine residues in the kinase activation loop or in the $\mathrm{C}$-terminal tail, which increases enzymatic activities. These activities stimulate intracellular signaling cascades and lead to increased cellular activities. Different strategies using various candidate therapeutic agents were applied to block c-MET/RON signaling pathways. ity $^{[16,17]}$. The extracellular sequences of c-MET/RON contain functional domains such as sema that regulate ligand binding, receptor dimerization, and phosphorylation ${ }^{[18]}$. c-MET is recognized by HGF, also known as scatter factor ${ }^{[19]}$. The specific ligand for RON is macrophage-stimulating protein (MSP), also known as HGF-like protein ${ }^{[12,20]}$. c-MET and HGF are distributed and expressed in various types of cells and tissues ${ }^{[21]}$. In contrast, $\mathrm{RON}$ is highly restricted in cells of epithelial origin, and MSP is produced mainly by liver cells ${ }^{[22,23]}$.

Ligand-dependent or independent activation of c-MET/ RON results in cell proliferation, migration, and matrix invasion, collectively known as invasive growth ${ }^{[11,12]}$. These activities facilitate epithelial cell transformation and malignant progression. The roles of c-MET/RON in cancer pathogenesis are supported by the following evidence. First, oncogenic mutations in the c-MET gene occur during the early stages of tumorigenesis in certain types of cancers ${ }^{[24]}$, suggesting that aberrant c-MET activation contributes to tumor initiation. Mutations in the RON gene have not been reported in primary tumors; however, aberrant splicing, resulting in formation of oncogenic RON variants, is frequently observed in primary tumors such as colon and breast cancers ${ }^{[25]}$. Second, c-MET/ RON overexpression exists in various types of primary and metastatic tumors ${ }^{[21,22]}$, indicating that c-MET/RON overexpression is involved in tumorigenic progression. Moreover, increased c-MET/RON expression is a validated prognostic factor for predicting disease progression and survival rate in certain cancer patients ${ }^{[26,27]}$. Third, c-MET/RON activation promotes a malignant phenotype in cancer cells. In tumor cells overexpressing c-MET/RON, cells undergo epithelial to mesenchymal transition (EMT), featuring spindle-like morphology, diminished E-cadherin expression, and increased vimentin expression ${ }^{[28,29]}$. EMT is a unique phenotype observed in cancer stem cells and a critical process required for cancer metastasis ${ }^{[30]}$. Fourth, altered c-MET/RON expression results in increased survival and pro-apoptotic activity of tumor cells ${ }^{[11,12]}$, which sustains tumor growth under hostile conditions such as hypoxia. Fifth, abnormality in c-MET/ RON expression contributes to the acquired resistance to conventional chemoagents $^{[31,32]}$. Recently, acquired resistance by lung cancers treated with SMIs was attributed to amplification of the c-MET gene and protein expression ${ }^{[33,34]}$. We have recently observed that down-regulation of c-MET/RON expression under chronic hypoxia is a mechanism that contributes to the insensitivity of tumor cells toward SMI-induced inhibitory or cytotoxic activity ${ }^{[35]}$. Given that hypoxia selectively advances tumor cells with malignant phenotypes ${ }^{[36]}$, our observation provides a mechanistic insight into the development of acquired resistance in hypoxic tumor cells. Clearly, aberrant c-MET/RON expression participates in tumor formation and malignant progression. Such activities also provide the molecular basis of targeting c-MET/RON for potential therapeutic intervention.

The principle of targeted cancer therapy is to aim at oncogenic molecules that dictate survival and growth of tumor cells, a process known as oncogene addiction ${ }^{[10]}$. Oncogene 
addiction such as dependence of breast and colon cancers on aberrant EGFR signaling is the rationale for the clinical use of mAbs or SMIs specific to EGFR family members. The c-MET-addicted phenotype has consistently been observed in some established cell lines from gastric and lung carcinomas $^{[13]}$. Amplification of the c-MET gene seems to be required for establishment of such addiction ${ }^{[13]}$. Cell lines from colon, breast, and pancreatic cancers, which are addicted to RON signaling at variable levels, have also been reported ${ }^{[12]}$. One study even showed the death of pancreatic cancer BxPC-3 cells after RON gene expression was silenced by specific siRNA ${ }^{[32]}$. Thus, oncogenic addiction of c-MET/RON signaling occurs in a fraction of tumor cells. Inhibition of tumor growth and induction of tumor cell apoptosis by specific mAbs or SMIs clearly indicates that c-MET/RON signaling is integrated into the cell survival or growth machinery ${ }^{[37,38]}$. Recent data from clinical trials using specific c-MET/RON inhibitors further confirm this observation ${ }^{[14,15]}$.

\section{Strategies and mechanism of blocking c-MET/RON path- ways}

Various strategies have been reported to block c-MET/RON pathways (Figure 1). These studies establish pharmaceutical feasibility, technological capability, and mechanistic understanding for blocking c-MET/RON signaling for targeted cancer treatment. Studies of blocking ligand-receptor interaction using decoy receptors ${ }^{[39,40]}$, soluble variants ${ }^{[41,42]}$, or ligandspecific $\mathrm{mAbs}^{[43]}$ have shown that such approaches are capable of impairing c-MET/RON-mediated tumorigenic activity both in vitro and in vivo. The soluble c-MET sema domain is a potent antagonist that inhibits c-MET-mediated tumor growth in vivo ${ }^{[41]}$. A splicing variant of RON comprising the sema domain also inhibits MSP binding to RON and blocks RON-mediated signaling and cell migration ${ }^{[42]}$. Anti-HGF antibodies AMG102 are able to inhibit HGF binding to c-MET and prevent c-MET activation ${ }^{[43]}$. Given that c-MET overexpression often coexists with HGF synthesis in stromal tissues around tumor masses as HGF:c-MET autocrine loops ${ }^{[4]}$, inhibition of the HGF:c-MET axis is also a rational approach for cancer treatment. However, these methods have limitations due to ligand-independent c-MET/RON activation caused by genetic mutation, gene amplification, protein overexpression, and generation of constitutively active variants.

Reduction of c-MET/RON density on the cell surface by $\mathrm{mAb}$-induced receptor ectodomain shedding and internalization is an effective method of impairing c-MET-RON signaling $^{[45,46]}$. Treatment of tumor cells with mAb DN30 specific to c-MET efficiently down-regulates c-MET expression through a mechanism involving proteolytic cleavage, leading to c-MET ectodomain shedding and intracellular degradation ${ }^{[45]}$. We have recently shown that the mAbs $\mathrm{Zt} / \mathrm{g} 4$ and $\mathrm{Zt} / \mathrm{f} 2$ specifically down-regulate RON expression by various colon cancer cells through a proteasomal pathway ${ }^{[46]}$. This reduction leads to diminished tumorigenic activity in vitro ${ }^{[46]}$, which could be a mechanism that impairs tumor growth.

The siRNA-mediated silencing of c-MET/RON mRNA expression has therapeutic value ${ }^{[47,48]}$. In lung cancer cells, silencing c-MET expression results in significant growth inhibition, $\mathrm{G}_{1}-\mathrm{S}$ arrest, and apoptosis ${ }^{[48]}$. Similar observations were made in colon cancer cells overexpressing RON after siRNA treatment ${ }^{[47]}$. Moreover, silencing RON expression by specific siRNA inhibits tumor growth in animal models ${ }^{[49]}$. Nevertheless, the inhibitory effect of siRNA was not observed in cancer cells without c-MET/RON gene amplification or protein overexpression $^{[47,48]}$. Thus, a precondition is required for the success of the siRNA-mediated therapy. These observations also suggest that selection of cancers with gene amplification or protein overexpression could lead to therapeutic success.

Several SMIs highly selective to c-MET or RON, or both, have been synthesized, and their effects are under preclinical or clinical evaluation ${ }^{[3,13]}$. The mechanism of SMI consists of the following categories ${ }^{[50]}$ : a) competitive binding to an ATP binding site when the kinase is in its active conformation, b) binding to non-active conformation of an ATP binding site of the kinase, c) allosteric inhibition by binding to a site other than an ATP binding pocket, and d) covalent inhibition by irreversible binding to an ATP binding pocket. The action of c-MET/RON SMI is mediated either by non-ATPcompetitive means (such as ARQ197 from ArQule/Daiichi) ${ }^{[38]}$ or by an ATP-competitive mechanism (such as PF-2341066 from Pfizer $)^{[3,13]}$. Because of the high degree of similarity in the kinase domains of the c-MET and the RON receptors, these SMIs often show a dual inhibitory effect, with slight differences in $\mathrm{IC}_{50}$ values. SMIs highly specific to c-MET are available ${ }^{[3,13,38]}$, and dual SMIs to both MET and RON have also been synthesized ${ }^{[51]}$. Moreover, SMIs highly specific to RON with only residual activity to c-MET have been reported ${ }^{[52]}$. The availability of such highly specific SMIs could help to define the pathogenic roles of c-MET or RON in certain types of cancer.

\section{Specific c-MET/RON therapeutics in clinical trials}

The evaluation of various c-MET/RON candidate drugs that are currently in phase I or phase II trials is detailed in several recent reviews ${ }^{[4,13,44]}$. Owing to space constraints, this section focuses on the most recently available information from a selected group of specific c-MET/RON mAbs and SMIs.

\section{Therapeutic mAbs specific to HGF or C-MET}

Several anti-HGF mAbs, including AMG102, SCH900105, and TAK-701, are currently undergoing clinical trials (Table $1)^{[13-15,44]}$. AMG102, which will be described here in detail, is a fully human IgG2 neutralizing mAb developed by Amgen ${ }^{[43]}$. AMG102 specifically binds to the HGF $\beta$-chain with a $K_{d}$ of $0.22 \mathrm{nmol} / \mathrm{L}$ and blocks the HGF-c-MET interaction with an $\mathrm{IC}_{50}$ of $2.1 \mathrm{nmol} / \mathrm{L}^{[43]}$. In preclinical paracrine HGF models, AMG102 potently inhibits c-MET-dependent tumor growth ${ }^{[44]}$. Phase I trials of AMG102 have been completed, yielding a favorable pharmacokinetic profile ${ }^{[44]}$. The mean half-life of AMG102 is about $15.4 \mathrm{~h}^{[14,15]}$. The dose of AMG102 is well tolerated up to the planned maximum dose of $20 \mathrm{mg} / \mathrm{kg}$. Treatment-related adverse events, including fatigue, constipa- 
Table 1. Potential Therapeutic Monoclonal Antibodies Specific to HGF, c-MET, and RON*.

\begin{tabular}{|c|c|c|c|c|c|}
\hline AMG102 (rilotumumab) & Amgen & HGF & Phase II & SCLC, CRC, Gliomas, PSC, RCC, GC, EC, Mesothelioma, and OC & 43 \\
\hline TAK-701 & Millennium & HGF & Phase I & Advanced non-hematological malignancies & 44 \\
\hline L2G7 & Galaxy Biotech & HGF & Preclinical & N/A & 69 \\
\hline MetMAb & Genetech & C-MET & Phase II & Locally advanced or metastatic solid tumors; advanced NSCLC & 54 \\
\hline $\mathrm{Zt} / \mathrm{f2}$ & TTUHSC & RON & Preclinical & $\mathrm{N} / \mathrm{A}$ & 57 \\
\hline
\end{tabular}

* All information about individual antibodies in clinical trials are from the website: http://clinicaltrials.gov, a service of the US National Institutes of Health. BC, breast cancer; EC, esophagus cancer; GC, gastric cancer; HCC, hepatocellular carcinoma; NSCLC, non-small cell lung cancer; OC, ovarian cancer; and PSC, prostate cancer. RCC, renal cell carcinoma; and SCLC, small-cell lung cancer.

tion, anorexia, nausea, and vomiting, are generally mild ${ }^{[14,15]}$. In phase II trials involving 23 patients with advanced solid tumors, $70 \%$ of patients had a best response of stable disease, with progression-free survival ranging from 8 to 40 weeks ${ }^{[14]}$. In another study, AMG102 was used in combination with bevacizumab to treat patients with advanced solid tumors such as colon and breast cancers ${ }^{[15]}$. Bevacizumab is a humanized $\mathrm{mAb}$ that recognizes and blocks VEGF-A, leading to inhibition of VEGFR activation ${ }^{[53]}$. In 14 evaluated patients, the combination of AMG102 with bevacizumab appeared to have an acceptable profile without dose-limiting toxicities. Treatmentemergent adverse events among patients receiving AMG102 plus bevacizumab are generally mild and include fatigue, nausea, constipation, and peripheral edema ${ }^{[15]}$. Bevacizumab does not seem to affect the pharmacokinetics of AMG102. More importantly, AMG102 in combination with bevacizumab leads to a best result of no tumor progression (stable disease) in 9 of 10 evaluable patients. Eight of 10 evaluable patients showed a reduction in tumor dimension, although no partial or complete responses occurred. Stable diseases with a duration of $\geq 8$ and $\geq 16$ weeks were noted in nine and seven patients, respectively, and four patients maintained stable disease for $\geq 24$ weeks ${ }^{[15]}$. These data suggest that AMG102-mediated c-MET inhibition synergizes with anti-VEGF-mediated angiogenic activity to contain tumor cell growth. Clearly, investigation of AMG102 in combination with other anti-cancer agents should also be pursued to enhance the therapeutic efficacy.

The single-armed MetMAb is a humanized anti-c-MET antibody from Genentech ${ }^{[54]}$. MetMAb binds to c-MET with an $\mathrm{IC}_{50}$ of $2.6-8.7 \mathrm{nmol} / \mathrm{L}$ in intact cells and diminishes c-MET density on the cell surface ${ }^{[54]}$. Phase I clinical trials have revealed that MetMAb is safe and well tolerated as a single agent at doses up to $30 \mathrm{mg} / \mathrm{mL}^{[55]}$. Phase II clinical trials evaluating MetMAb in combination with erlotinib for second- and third-line metastatic non-small-cell lung cancer are ongoing ${ }^{[66]}$. Given that c-MET over-expression is known to diminish EGFR-targeted therapy ${ }^{[33,34]}$, MetMAb-mediated c-MET inhibition could show a clinical benefit in these tumors.

\section{Candidate mAbs specific to RON}

Potential anti-RON mAbs are IMC-41A10, a fully human IgG1 $\mathrm{mAb}$ (Imclone Inc) ${ }^{[37]}$, and $\mathrm{Zt} / \mathrm{f} 2$, a mouse IgG2a mAb (from our laboratory $)^{[57]}$. Both $\mathrm{mAbs}$ are still at the preclinical stage. IMC-41A10 binds to RON with an $\mathrm{ED}_{50}$ of $0.15 \mathrm{nmol} / \mathrm{L}$ and blocks MSP interaction with RON. In colon, breast and pancreatic xenograft tumor models, IMC-41A40 inhibits tumor growth by $50 \%-60 \%$ as a single agent. These effects seem to be linked to IMC-41A40-induced inhibition of RON activation and its downstream signaling pathways ${ }^{[37]}$.

$\mathrm{Zt} / \mathrm{f} 2$ binds to RON and its oncogenic variants such as RON160 with an $\mathrm{ED}_{50}$ of $2.3 \mathrm{nmol} / \mathrm{L}$. Zt/f2 interacts with an epitope(s) on the RON extracellular domain essential for RON maturation and activation ${ }^{[57]}$. Binding of $\mathrm{Zt} / \mathrm{f} 2$ effectively induces RON internalization, which diminishes RON expression and impairs downstream signal activation. Administration of $\mathrm{Zt} / \mathrm{f} 2$ as a single agent into Balb/c mice results in partial inhibition of tumor growth caused by transformed NIH3T3 cells expressing oncogenic RON160. Colon cancer HT-29 cell-induced tumor growth in athymic nude mice was also attenuated following $\mathrm{Zt} / \mathrm{f} 2$ treatment. In both cases, an inhibition of $\sim 50 \%$ of tumor growth was achieved ${ }^{[57]}$. Moreover, $\mathrm{Zt} / \mathrm{f} 2$ in combination with 5-fluorouracil showed a synergistic effect on HT-29 cell-induced tumor growth in vivo (our unpublished data). Another strategy that enhances therapeutic efficacy of $\mathrm{Zt} / \mathrm{f} 2$ is conjugating cytotoxic drugs for increased cancer cell killing. Studies using $\mathrm{Zt} / \mathrm{f} 2$-directed immunoliposome loaded with doxorubicin have shown increased cytotoxic activities against various cancer cells in vitro ${ }^{[58]}$. Thus, Zt/ $\mathrm{f} 2$ is a potential therapeutic mAb capable of inhibiting RONmediated oncogenesis by colon cancer cells in animal models.

\section{Specific c-MET/RON SMIs in clinical studies}

More than 10 SMIs relevant to c-MET/RON inhibition are at various stages of clinical trials (Table 2$)^{[4,13,44]}$. The majority of these SMIs are specific to c-MET. The representatives are ARQ197 (ArQule/Daiichi Sankyo) and PF-02341066 (Pfizer) $^{[4,38,44]}$. ARQ197 is a c-MET-selective and non-ATP- 
Table 2. Selective Small Molecule Tyrosine Kinase Inhibitors Specific to c-MET and RON*.

\begin{tabular}{|c|c|c|c|c|c|}
\hline Compound & Manufacturer & Targeted RTKs & Status & Descriptions in clinical trials & Ref \\
\hline ARQ197 & $\begin{array}{l}\text { ArQule/Daiichi } \\
\text { Sankyo }\end{array}$ & c-MET & Phase II & $\begin{array}{l}\text { Advanced solid (prostate) tumor; HCC; locally advanced, } \\
\text { inoperable or metastatic primary solid tumors; advanced } \\
\text { HCC, RCC, BC, NSCLC and melanoma }\end{array}$ & 38 \\
\hline XL184 & Exelixis & C-MET & Phase $\mathrm{I} / \mathrm{II} / \mathrm{III}$ & $\begin{array}{l}\text { MTC, PCAC, PSC, HCC, GE(GE)JC; Melanoma, SCLC, } \\
\text { OC, PFTC, BC, NSCLC, and GM }\end{array}$ & 74 \\
\hline $\begin{array}{l}\text { PF-02341066 } \\
\text { (crizotinib) }\end{array}$ & Pfizer & c-MET/ALK & Phase I/II & $\begin{array}{l}\text { Advanced NSCLC; anaplastic LCL; relapsed/refractory } \\
\text { solid tumors, primary CNS Tumors }\end{array}$ & 44 \\
\hline $\begin{array}{l}\text { EMD 1214063/ } \\
\text { EMD } 1204831\end{array}$ & EMD Serono & C-MET & Phase I/II & Advanced, refractory solid tumors & 71 \\
\hline $\begin{array}{l}\text { GSK1363089 } \\
\text { (Foretinib) }\end{array}$ & GlaxoSmithKline & c-MET/KDR/RON & Phase I/II & PRCC, AMCC, DEAGC; GE(GE)JC & 72 \\
\hline MGCD265 & MethylGene Inc & $\begin{array}{l}\text { c-MET/VEGFR/ } \\
\text { RON/Tie-2 }\end{array}$ & Phase I/II & Advanced metastatic/ unresectable malignancies & 73 \\
\hline JNJ-38877605 & Johnson \& Johnson & c-MET & Phase I & Advanced/refractory solid tumors & 13 \\
\hline PHA665752 & Pfizer & c-MET/RON & Preclinical & $\mathrm{N} / \mathrm{A}$ & 13 \\
\hline Compound I & Amgen & c-MET/RON & Preclinical & $\mathrm{N} / \mathrm{A}$ & 51 \\
\hline
\end{tabular}

* All information about individual inhibitors in clinical trials are derived from the website: http://clinicaltrials.gov, a service of the US National Institutes of Health. AMCC, advanced/metastatic gastric carcinoma; BC, breast cancer; DEAGC, distal esophageal adenocarcinoma gastric cancer; GE(GE)JC, gastro esophageal (GE) junction cancer; GM, glioblastoma multiforme; HCC, hepatocellular carcinoma, LCL, large-cell lymphoma; MTC, medullary thyroid cancer; NSCLC, non-small cell lung cancer; PFTC, peritoneal or fallopian tube carcinoma; PRCC, papillary renal-cell carcinoma; and RCC, renal cell carcinoma.

competitive SMI. Preclinical data have demonstrated that ARQ197 inhibits c-MET activation in various human tumor cell lines and shows anti-tumor activity against several human tumor xenografts ${ }^{[38]}$. A phase I dose-escalation study in patients with metastatic cancers shows that ARQ197 is well tolerated and has resulted in tumor responses and prolonged stable disease across broad ranges of tumors and doses $^{[4,38,44,59]}$. ARQ197 is currently in phase II trials as a single agent for germ cell tumors (GCT), including testicular and non-central nervous system (non-CNS) tumors ${ }^{[59]}$. Also under way is a phase I/II clinical trial designed to evaluate the safety of ARQ197 administered in combination with irinotecan and cetuximab in patients with metastatic colorectal cancer who possess the wild-type KRAS gene ${ }^{[59]}$.

PF-02341066 (crizotinib) is an ATP-competitive SMI highly specific to c-MET and anaplastic lymphoma kinase (ALK) ${ }^{[60]}$. The features of PF-02341066 include a) suppression of c-METdependent proliferation, migration and invasion of various cancer cells; b) inhibition of HGF-induced endothelial cell survival or serum-stimulated tubulogenesis; and c) high potency against a variety of c-MET mutants compared to wild-type c-MET ${ }^{[60]}$. These data suggest that PF-02341066 has a broad antitumor profile in terms of regulating proliferation, angio- genesis, and abnormalities in c-MET mutants. PF-02341066 is currently in various stages of clinical trials as a single agent or in combination with chemoagents for patients with advanced tumors, including non-small-cell lung cancer and anaplastic large cell lymphoma ${ }^{[61]}$. A recent report found that PF-02341066 was highly effective in 82 patients with nonsmall-cell lung cancer harboring aberrant ALK expression ${ }^{[62]}$. Given that PF-02341066 is a dual c-MET/ALK SMI, it would be interesting to see whether it displays similar efficacy in cancers with a c-MET abnormality.

Development of RON-specific SMIs is still in progress. Compound I (Amgen), a dual inhibitor of c-MET/RON, was identified in $2008^{[51]}$. It selectively inhibits the kinase activities of c-MET and RON with $\mathrm{IC}_{50}$ values of 4 and $9 \mathrm{nmol} / \mathrm{L}$, respectively. Compound I inhibits c-MET/RON-mediated cell migration in vitro and causes partial inhibition of tumor growth mediated by an oncogenic RON160 variant ${ }^{[51]}$. Recently, a novel series of potent RON SMIs was identified through chemical designing and synthesis ${ }^{[52]}$. The most attractive products, Compounds 4 and 13, selectively inhibited RON kinase activity with $\mathrm{IC}_{50}$ values of 0.05 and $0.06 \mu \mathrm{mol} / \mathrm{L}$, respectively, in a cell-based assay and showed only residual activity against c-MET and no significant inhibitory activity 
against VEGFR and other RTKs ${ }^{[52]}$. Clearly, the synthesis of RON-specific SMIs provides a platform for the development of more efficient RON-specific therapeutics for clinical evaluation. However, altered expression of c-MET and RON often coexist in various cancers, and the feasibility of developing an SMI specific to RON still needs to be investigated in terms of technological feasibility and clinical benefits.

\section{Acquired resistance to SMIs specific to c-MET/RON}

Acquired resistance by advanced cancers to SMIs such as gefitinib and erlotinib, which are specific to EGFR, is a serious challenge in the treatment of cancer patients ${ }^{[63]}$. One of the mechanisms recently discovered in gefitinib insensitivity is c-MET gene amplification in resistant cells, which leads to activation of ERBB3 signaling ${ }^{[6,63]}$. Increased HGF production by tumor cells also induces gefitinib resistance of lung cancer cells harboring EGFR-activating mutation ${ }^{[65,66]}$. In this case, HGF-mediated hyposensitivity acts as a novel mechanism of resistance to both reversible and irreversible EGFR SMIs ${ }^{[6,66]}$. Although c-MET/RON-specific SMIs are still in clinical trials, it is predicted that acquired resistance to these SMIs will emerge. This notion is supported by a recent in vitro study showing that tumor cells acquire resistance to c-MET-specific SMIs such as PF-02341066 $6^{[67]}$. Under such conditions, a cellular switch by tumor cells to EGFR signaling dependence leads to the resistance in these tumor cells ${ }^{[67]}$. These results suggest that crosstalk between c-MET and EGFR family members is the mechanistic cause that results in the escape of cancer cells from SMI-mediated cytotoxic or inhibitory activity. It is believed that as more SMIs are used clinically, additional novel mechanisms relevant to acquired resistance will be discovered, which should stimulate more research in this field.

We recently uncovered another novel mechanism by which cancer cells acquire resistance to a dual c-MET/RON-specific $\mathrm{SMI}^{[35]}$. It was previously observed that hypoxia-induced down-regulation of c-MET/RON expression contributes to acquisition of resistance to c-MET/RON dual inhibitor Compound $\mathrm{I}^{[51]}$. Diminished c-MET/RON expression under chronic hypoxia results in an insensitivity of tumor cells to Compound I-induced growth inhibition. These findings have clinical relevance because hypoxia affects therapeutic efficiency of SMIs in treatment of c-MET/RON-expressing tumors. Studies are currently under way to determine the mechanisms by which hypoxia regulates acquired resistance to specific c-NET/RON inhibitors.

\section{Future directions}

The evidence that c-MET/RON plays a critical role in cancer development is overwhelming, which provides the rationale to target these two receptors for cancer therapy. Over the past several years, specific c-MET/RON inhibitors have advanced from the laboratory to the clinic with promising outcomes. However, these achievements are only beginning to unveil the clinical significance of c-MET/RON-targeted therapy. The goals we must address in the near future include: a) selection of the most suitable cancer types or patient population; b) assessment of immediate clinical benefit and long-term effectiveness; c) evaluation of an agent both alone and in combination with chemotherapy or radiation; d) development of acquired drug resistance and the underlying mechanisms; e) improvement of the next generation of SMI or $\mathrm{mAb}$; and $\mathrm{f}$ ) potential mechanisms of the therapeutic activity. The progress in the study of c-MET/RON-specific therapeutics certainly provides the opportunity to meet these challenges.

\section{Acknowledgements}

This work was supported in part by grant R01 CA91980 from the National Cancer Institute of the US National Institutes of Health and the Amarillo Area Foundation of Texas (to Dr Ming-Hai WANG). We apologize to the authors of many publications relevant to the topic covered in this review that we were unable to cite because of space constraints. We are grateful to Ms K BOHN (Texas Tech University, Amarillo, TX) for editing the manuscript.

\section{References}

1 Ciardiello F, Tortora C. EGFR antagonists in cancer treatment. N Engl J Med 2008; 358: 1160-74.

2 Zwick E, Bange J, Ullrich A. Receptor tyrosine kinase signaling as a target for cancer intervention strategies. Endocr Relat Cancer 2001; 8: 161-73.

3 Dussault I, Bellon SF. From concept to reality: the long road to c-Met and RON receptor tyrosine kinase inhibitors for the treatment of cancer. Anticancer Agents Med Chem 2009; 9: 221-25.

4 Liu X, Newton RC, Scherle PA. Developing c-MET pathway inhibitors for cancer therapy: progress and challenges. Trends Mol Med 2010; 16: $37-45$.

5 Hubbard SR, Miller WT. Receptor tyrosine kinases: mechanisms of activation and signaling. Curr Opin Cell Biol 2007; 19: 117-23.

$6 \mathrm{Xu} \mathrm{AM}$, Huang PH. Receptor tyrosine kinase coactivation networks in cancer. Cancer Res 2010; 70: 3857-60.

7 Robertson SC, Tynan JA, Donoghue DJ. RTK mutations and human syndromes when good receptors turn bad. Trends Genet 2000; 16: 265-71.

8 Porter AC, Vaillancourt RR. Tyrosine kinase receptor-activated signal transduction pathways which lead to oncogenesis. Oncogene 1998; 17: 1343-52.

9 Blume-Jensen P, Hunter T. Oncogenic kinase signaling. Nature 2001; 411: 355-65.

10 Weinstein IB, Joe AK. Mechanisms of disease: Oncogene addiction-a rationale for molecular targeting in cancer therapy. Nat Clin Pract Oncol 2006; 3: 448-57.

11 Benvenuti S, Comoglio PM. The MET receptor tyrosine kinase in invasion and metastasis. J Cell Physiol. 2007; 213: 316-25.

12 Wagh PK, Peace BE, Waltz SE. Met-related receptor tyrosine kinase Ron in tumor growth and metastasis. Adv Cancer Res 2008; 100: 1-33.

13 Comoglio PM, Giordano S, Trusolino L. Drug development of MET inhibitors: targeting oncogene addiction and expedience. Nat Rev Drug Discov 2008; 7: 504-16.

14 Gordon MS, Sweeney CS, Mendelson DS, Eckhardt SG, Anderson A, Beaupre DM, et al. Safety, pharmacokinetics, and pharmacodynamics of AMG 102, a fully human hepatocyte growth factor-neutralizing monoclonal antibody, in a first-in-human study of patients with advanced solid tumors. Clin Cancer Res 2010; 16: 699-710. 
15 Rosen PJ, Sweeney CJ, Park DJ, Beaupre DM, Deng H, Leitch IM, et al. A phase lb study of AMG 102 in combination with bevacizumab or motesanib in patients with advanced solid tumors. Clin Cancer Res 2010; 16: 2677-87.

16 Ronsin C, Muscatelli F, Mattei MG, Breathnach R. A novel putative receptor protein tyrosine kinase of the met family. Oncogene 1993; 8 : 1195-202.

17 Park M, Dean M, Kaul K, Braun MJ, Gonda MA, Vande Woude G. Sequence of MET protooncogene CDNA has features characteristic of the tyrosine kinase family of growth-factor receptors. Proc Natl Acad Sci USA 1987; 84: 6379-83.

18 Gherardi E, Love CA, Esnouf RM, Jones EY. The sema domain. Curr Opin Struct Biol 2004; 14: 669-78.

19 Vigna E, Naldini L, Tamagnone L, Longati P, Bardelli A, Maina F, et al. Hepatocyte growth factor and its receptor, the tyrosine kinase encoded by the C-MET proto-oncogene. Cell Mol Biol 1994; 40: $597-$ 604.

20 Wang MH, Ronsin C, Gesnel MC, Coupey L, Skeel A, Leonard EJ, et al. Identification of the ron gene product as the receptor for the human macrophage stimulating protein. Science 1994; 266: 117-9. ,

21 Zarnegar R, DeFrances MC. Expression of HGF-SF in normal and malignant human tissues. EXS 1993; 65: 181-99.

22 Wang MH, Lee W, Luo YL, Weis MT, Yao HP. Altered expression of the RON receptor tyrosine kinase in various epithelial cancers and its contribution to tumorigenic phenotypes in thyroid cancer cells. J Pathol 2007; 213: 402-11.

23 Wang MH, Zhou YQ, Chen YQ. Macrophage-stimulating protein and RON receptor tyrosine kinase: potential regulators of macrophage inflammatory activities. Scand J Immunol 2002; 56: 545-53.

24 Krishnaswamy S, Kanteti R, Duke-Cohan JS, Loganathan S, Liu W, Ma $\mathrm{PC}$, et al. Ethnic differences and functional analysis of MET mutations in lung cancer. Clin Cancer Res 2009; 15: 5714-23.

$25 \mathrm{Lu} \mathrm{Y,} \mathrm{Yao} \mathrm{HP,} \mathrm{Wang} \mathrm{MH.} \mathrm{Multiple} \mathrm{variants} \mathrm{of} \mathrm{the} \mathrm{RON} \mathrm{receptor} \mathrm{tyrosine}$ kinase: biochemical properties, tumorigenic activities, and potential drug targets. Cancer Lett 2007; 257: 157-64

26 Lee CT, Chow NH, Su PF, Lin SC, Lin PC, Lee JC. The prognostic significance of RON and MET receptor coexpression in patients with colorectal cancer. Dis Colon Rectum 2008; 51: 1268-74.

27 Ponzo MG, Lesurf R, Petkiewicz S, O'Malley FP, Pinnaduwage D, Andrulis IL, et al. Met induces mammary tumors with diverse histologies and is associated with poor outcome and human basal breast cancer. Proc Natl Acad Sci USA 2009; 106: 12903-8.

28 Wang Z, Sandiford S, Wu C, Li SS. Numb regulates cell-cell adhesion and polarity in response to tyrosine kinase signaling. EMBO J 2009; 28: $2360-73$.

29 Wang D, Shen Q, Chen YQ, Wang MH. Collaborative activities of macrophage-stimulating protein and transforming growth factor-beta1 in induction of epithelial to mesenchymal transition: roles of the RON receptor tyrosine kinase. Oncogene 2004; 23: 1668-80.

30 Acloque H, Adams MS, Fishwick K, Bronner-Fraser M, Nieto MA. Epithelial-mesenchymal transitions: the importance of changing cell state in development and disease. J Clin Invest 2009; 119: 143849.

31 Fan S, Meng Q, Laterra JJ, Rosen EM. Role of Src signal transduction pathways in scatter factor-mediated cellular protection. J Biol Chem 2009; 284: 7561-77.

32 Logan-Collins J, Thomas RM, Yu P, Jaquish D, Mose E, French R, et al. Silencing of RON receptor signaling promotes apoptosis and gemcitabine sensitivity in pancreatic cancers. Cancer Res 2010; 70 : 1130-40.

33 Bean J, Brennan C, Shih JY, Riely G, Viale A, Wang L, et al. MET amplification occurs with or without T790M mutations in EGFR mutant lung tumors with acquired resistance to gefitinib or erlotinib. Proc Natl Acad Sci USA 2007; 104: 20932-7.

34 Turke AB, Zejnullahu K, Wu YL, Song Y, Dias-Santagata D, Lifshits E, et al. Preexistence and clonal selection of MET amplification in EGFR mutant NSCLC. Cancer Cell 2010; 17: 77-88.

35 Guin S, Wang MH. Down-regulation of MET/RON receptor tyrosine kinases in colon cancer cells under chronic hypoxia as a mechanism for resistance towards targeted therapy. 101th AACR Annual Meeting: 2010, April 7-21; Washington, DC. Abstr442.

36 Semenza GL. Defining the role of hypoxia-inducible factor 1 in cancer biology and therapeutics. Oncogene 2010; 29: 625-34.

37 O'Toole JM, Rabenau KE, Burns K, Lu D, Mangalampalli V, Balderes $\mathrm{P}$, et al. Therapeutic implications of a human neutralizing antibody to the macrophage-stimulating protein receptor tyrosine kinase (RON), a C-MET family member. Cancer Res 2006; 66: 9162-70.

38 Munshi N, Jeay S, Li Y, Chen CR, France DS, Ashwell MA, et al. ARQ 197, a Novel and Selective Inhibitor of the Human c-Met Receptor Tyrosine Kinase with Antitumor Activity. Mol Cancer Ther 2010; 9: 1544-53.

39 Kong-Beltran M, Stamos J, Wickramasinghe D. The Sema domain of Met is necessary for receptor dimerization and activation. Cancer Cell 2004; 6: 75-84

40 Michieli P, Mazzone M, Basilico C, Cavassa S, Sottile A, Naldini L, et al. Targeting the tumor and its microenvironment by a dual-function decoy Met receptor. Cancer Cell 2004; 6: 61-73.

41 Tiran Z, Oren A, Hermesh C, Rotman G, Levine Z, Amitai H, et al. A novel recombinant soluble splice variant of Met is a potent antagonist of the hepatocyte growth factor/scatter factor-Met pathway. Clin Cancer Res 2008; 14: 4612-21.

42 Ma Q, Zhang K, Yao HP, Zhou YQ, Padhye S, Wang MH. Inhibition of MSP-RON signaling pathway in cancer cells by a novel soluble form of RON comprising the entire sema sequence. Int J Oncol 2010; 36: 1551-61.

43 Jun HT, Sun J, Rex K, Radinsky R, Kendall R, Coxon A, et al. AMG 102, a fully human anti-hepatocyte growth factor/scatter factor neutralizing antibody, enhances the efficacy of temozolomide or docetaxel in U-87 MG cells and xenografts. Clin Cancer Res 2007; 13: 6735-42.

44 Cecchi F, Rabe DC, Bottaro DP. Targeting the HGF/Met signaling pathway in cancer. Eur J Cancer 2010; 46: 1260-70.

45 Petrelli A, Circosta P, Granziero L, Mazzone M, Pisacane A, Fenoglio S, et al. Ab-induced ectodomain shedding mediates hepatocyte growth factor receptor down-regulation and hampers biological activity. Proc Natl Acad Sci USA 2006; 103: 5090-5.

46 Li Z, Yao H, Guin S, Padhye SS, Zhou YQ, Wang MH. Monoclonal antibodies-induced down-regualtion of RON receptor tyrosine kinase diminishes tumorigenic activities of colon cancer cells. Int J Oncol 2010; 37: 473-82.

47 Wang J, Rajput A, Kan JL, Rose R, Liu XQ, Kuropatwinski K, et al. Knockdown of Ron kinase inhibits mutant phosphatidylinositol 3-kinase and reduces metastasis in human colon carcinoma. J Biol Chem 2009; 284: 10912-22.

48 Lutterbach B, Zeng Q, Davis L, Hatch H, Hang G, Kohl NE, et al. Lung cancer cell lines harboring MET gene amplification are dependent on Met for growth and survival. Cancer Res 2007; 67: 2081-8.

49 Xu XM, Wang D, Shen Q, Chen YQ, Wang MH. RNA-mediated gene silencing of the RON receptor tyrosine kinase alters oncogenic phenotypes of human colorectal carcinoma cells. Oncogene 2004; 23: 8464-74.

50 Zhang J, Yang PL, Gray NS. Targeting cancer with small molecule kinase inhibitors. Nature Cancer Review 2009; 9: 28-39. 
et al. MET amplification leads to gefitinib resistance in lung cancer by activating ERBB3 signaling. Science 2007; 316: 1039-43.

51 Zhang Y, Kaplan-Lefko PJ, Rex K, Yang Y, Moriguchi J, Osgood T, et al. Identification of a novel recepteur d'origine nantais/c-met smallmolecule kinase inhibitor with antitumor activity in vivo. Cancer Res 2008; 68: 6680-7.

52 Raeppel S, Gaudette F, Mannion M, Claridge S, Saavedra O, Isakovic L, et al. Identification of a novel series of potent RON receptor tyrosine kinase inhibitors. Bioorg Med Chem Lett 2010; 20: 2745-9.

53 Grothey A, Galanis E. Targeting angiogenesis: progress with anti-VEGF treatment with large molecules. Nat Rev Clin Oncol 2009; 6: 507-18.

54 Jin H, Yang R, Zheng Z, Romero M, Ross J, Bou-Reslan H, et al. MetMAb, the one-armed 5D5 anti-c-Met antibody, inhibits orthotopic pancreatic tumor growth and improves survival. Cancer Res 2008; 68: 4360-8.

55 Salgia R et al. A phase I, open-label, dose-escalation study of the safety and pharmacology of MetMAb, a monovalent antagonist antibody to the receptor c-MET, administered IV in patients with locally advanced or metastatic solid tumors. In AACR-NCI-EORTC International Conference on Molecular Targets and Cancer Therapeutics. Abstract 441.

56 clinicaltrials.gov. <http://www.clinicaltrials.gov/ct2/results? term=METMAb>.

57 Wang MH, Yao HP, Chen LF, Lu Y, Zhang K. Therapeutical potentials of the monoclonal antibody $\mathrm{Zt} / 2 \mathrm{~F} 2$ for the malignant epithelial cancers overexpressing the RON receptor tyrosine kinase. 98th AACR Annual Meeting, 2007; Los Angeles, CA; Abstract 664.

58 Guin S, Yao HP, Wang MH. RON receptor tyrosine kinase as a target for delivery of chemodrugs by antibody directed pathway for cancer cell cytotoxicity. Mol Pharm 2010; 7: 386-97.

59 clinicaltrials.gov. <http://www.clinicaltrials.gov/ct2/results? term=ARQ197>

60 Zou HY, Li Q, Lee JH, Arango ME, McDonnell SR, Yamazaki S, et al. An orally available small-molecule inhibitor of c-Met, PF-2341066, exhibits cytoreductive antitumor efficacy through antiproliferative and antiangiogenic mechanisms. Cancer Res 2007; 67: 4408-17.

61 Kwak EL, Camidge DR, Clark, J. Shapiro GI, Maki RG, Ratain MJ, et al. Clinical activity observed in a phase I dose escalation trial of an oral c-met and alk inhibitor, PF-02341066. J Clin Oncol 2009; 27: 15s (Suppl: Abstr 3509).

62 Bang Y, Kwak EL, Shaw AT, Camidge DR, lafrate AJ, Maki RG, et al. Clinical activity of the oral ALK inhibitor PF-02341066 in ALK-positive patients with non-small cell lung cancer (NSCLC). J Clin Oncol 2010; 28: 18s (Suppl: Abstr 3).

63 Engelman JA, Zejnullahu K, Mitsudomi T, Song Y, Hyland C, Park JO,
64 Arteaga CL. HER3 and mutant EGFR meet MET. Nat Med 2007; 13: 675-7.

65 Yamada T, Matsumoto K, Wang W, Li Q, Nishioka Y, Sekido Y, et al. Hepatocyte growth factor reduces susceptibility to an irreversible epidermal growth factor receptor inhibitor in EGFR-T790M mutant lung cancer. Clin Caner Res 2010; 16: 174-83.

66 Yano S, Wang W, Li Q, Matsumoto K, Sakurama H, Nakamura T, et al. Hepatocyte growth factor induces gefitinib resistance of lung adenocarcinoma with epidermal growth factor receptor-activating mutations. Cancer Res 2008; 68: 9479-87.

67 McDermott U, Pusapati RV, Christensen JG, Gray NS, Settleman J. Acquired resistance of non-small cell lung cancer cells to MET kinase inhibition is mediated by a switch to epidermal growth factor receptor dependency. Cancer Res 2010; 70: 1625-34.

68 Petrelli A, Circosta P, Granziero L, Mazzone M, Pisacane A, Fenoglio S, et al. Ab-induced ectodomain shedding mediates hepatocyte growth factor receptor down-regulation and hampers biological activity. Proc Natl Acad Sci USA 2006; 103: 5090-5.

69 Kim KJ, Wang L, Su YC, Gillespie GY, Salhotra A, Lal B, Laterra J. Systemic anti-hepatocyte growth factor monoclonal antibody therapy induces the regression of intracranial glioma xenografts. Clin Cancer Res 2006; 12: 1292-8.

70 Meetze KA, Connolly K, Boudrow A, Venkataraman S, Medicherla S, Gyuris J, et al. Preclinical efficacy and pharmacodynamics of $\mathrm{SCH}$ 900105 (AV-299) an anti-HGF antibody in an intracranial glioblastoma model. Mol Cancer Ther 2009; 8 (12 Suppl): C181.

71 Walker K, Padhiar M. Molecular targets and cancer therapeutics Part 2 in AACR-NCI-EORTC - 21st International Symposium. iDrugs 2010; 13: 10-2.

72 Qian F, Engst S, Yamaguchi K, Yu P, Won KA, Mock L, et al. Inhibition of tumor cell growth, invasion, and metastasis by EXEL-2880 (XL880, GSK1363089), a novel inhibitor of HGF and VEGF receptor tyrosine kinases. Cancer Res 2009; 69: 8009-16

73 Kollmannsberger CK, Hurwitz H, Vlahovic G, Maroun C, Dumouchel J, Reid G, et al. Phase I study of daily administration of MGCD265 to patients with advanced malignancies (Study 265-101). J Clin Oncol 2009; 27 (suppl: abstr e14525).

74 Sugawara M, Geffner DL, Martinez D, Hershman JM. Novel treatment of medullary thyroid cancer. Curr Opin Endocrinol Diabetes Obes 2009; 16: 367-72. 